https://helda.helsinki.fi

\title{
Malpractice claims related to tooth extractions
}

\section{Koskela, Sanna}

2017-03

Koskela , S , Suomalainen , A , Apajalahti , S \& Venta , I 2017 , ' Malpractice claims related to tooth extractions ' , Clinical Oral Investigations , vol. 21 , no. 2 , pp. 519-522 . https://doi.org/10.1007/s00784-016-

http://hdl.handle.net/10138/234617

https://doi.org/10.1007/s00784-016-1896-y

publishedVersion

Downloaded from Helda, University of Helsinki institutional repository.

This is an electronic reprint of the original article.

This reprint may differ from the original in pagination and typographic detail.

Please cite the original version. 


\title{
Malpractice claims related to tooth extractions
}

\author{
Sanna Koskela $^{1} \cdot$ Anni Suomalainen $^{2} \cdot$ Satu Apajalahti $^{2} \cdot$ Irja Ventä $^{3}$
}

Received: 6 August 2015 / Accepted: 27 June 2016/Published online: 10 August 2016

(C) Springer-Verlag Berlin Heidelberg 2016

\begin{abstract}
Objective The aim of this study was to analyze malpractice claims related to tooth extractions in order to identify areas requiring emphasis and eventually to reduce the number of complications.

Material and methods We compiled a file of all malpractice claims related to tooth extractions (EBA code) between 1997 and 2010 from the Finnish Patient Insurance Centre. We then examined the data with respect to date, tooth, surgery, injury diagnosis, and the authority's decision on the case.

Results The material consisted of 852 completed patient cases. Most of the teeth were third molars (66\%), followed by first molars $(8 \%)$, and second molars $(7 \%)$. The majority of claims were related to operative extraction $(71 \%)$ followed by ordinary extraction (17\%) and apicoectomy of a singlerooted tooth $(7 \%)$ or multi-rooted tooth $(2 \%)$. The most common diagnosis was injury of the lingual or inferior alveolar nerve. According to the authority's decision, the patient received compensation more often in cases involving a third molar than other teeth (56 vs. $46 \%, P<0.05$ ).

Conclusion The removal of a mandibular third molar was the basis for the majority of malpractice claims.

Clinical relevance To reduce the numbers of lingual and inferior alveolar nerve injuries, the removal of mandibular third molars necessitates recent and high-quality panoramic
\end{abstract}

Irja Ventä

irja.venta@helsinki.fi

Oral Hammaslääkärit Dental Clinic, Helsinki, Finland

2 Department of Radiology, Helsinki University Hospital and University of Helsinki, Helsinki, Finland

3 Department of Oral and Maxillofacial Diseases, Faculty of Medicine, University of Helsinki, P.O. Box 41, FI-00014 University of Helsinki, Helsinki, Finland radiograph, preoperative assessment of the difficulty of removal, and consciousness of the variable anatomical course of the lingual nerve.

Keywords Molar third · Nerve injury · Postoperative complications $\cdot$ Reporting insurance claims $\cdot$ Oral surgery

\section{Introduction}

General practitioners perform most dental extractions, but articles about complications related to extractions are written mostly by oral and maxillofacial surgeons and involve third molars $[1,2]$. The most common complication related to third molar extraction is alveolitis (3.4\%), followed by delayed healing $(1.5 \%)$, and inferior alveolar nerve (IAN) damage $(1.0 \%)[2]$.

Although nerve injury as a complication of mandibular third molar removal is infrequent, in the malpractice register, this complication is the major reason for litigation. The incidence of lingual nerve (LN) and IAN injuries varies, but studies report an incidence of about $1 \%[3,4]$. In malpractice material related to third molar removals, these injuries are the diagnosis in $59 \%$ of cases [5].

In our earlier study with a smaller series of the present material, we aimed to determine whether the number of injuries to the IAN could be reduced with preoperative cone-beam computed tomography (CBCT). Despite the growing availability of CBCT, we found no evidence of a reduction in the number of nerve injuries [6].

The Finnish Patient Insurance Centre (FPIC) handles the compensation procedures for patient injuries that occur in Finland [7]. Since 1987, FPIC files have accumulated an enormous amount of data, and analyzing these data could shed light on ways to reduce the number of complications. 
Injured patients must apply for compensation within 3 years of the date the patient became aware of the injury. At the FPIC, the decision for compensation is based on documents from the healthcare providers and a statement of the medical adviser.

The aim of this study was to analyze malpractice claims related to tooth extractions in order to identify areas requiring emphasis and eventually to reduce the number of complications.

\section{Material and methods}

A file of all malpractice claims was compiled from FPIC records related to tooth extractions between 1997 and 2010. The search used the code for different types of tooth removal (EBA code, Table 1), and the classification code was based on the Nordic Classification of Surgical Procedures (NCSP) [8]. The search included all completed cases.

The data were examined with respect to the date of the decision on the case, the tooth, the type of surgery, the diagnosis of injury, and the authority's decision on the case.

The FPIC and the Ministry of Social Affairs and Health in Finland granted permission to use these register-based data for research purposes. No additional institutional ethics committee approval was necessary, as the study involved no patient interventions. Due to the retrospective nature of the study, the patients' informed consent was unnecessary.

The data were analyzed with Microsoft Excel spreadsheet software, and the chi-squared test served to detect the statistical significance of differences between frequencies. The level of significance was set at $P<0.05$.

\section{Results}

During the 14-year period, 852 patient cases related to tooth extractions were identified. The mean number of cases per year was 61 ( $\mathrm{SD} \pm 15.1$ cases).

The total number of teeth involved in this series was 1009 . An individual case can involve more than one tooth; for example, a case involving the operative extraction of mandibular first and second molars resulted in a claim for injury of the IAN, infection, and a mandibular fracture. The majority $(66 \%)$ of teeth involved in these claims were third molars (Fig. 1). Of these third molars, $90 \%(n=598$ teeth) were mandibular ones, and of the second and third largest groups of teeth (i.e., first and second molars, $n=148$ teeth), cases involved also more mandibular than maxillary teeth (66 vs. $34 \%, P<0.001)$.

Because of the statistically significant difference between the numbers of third molars and the other teeth (66 vs. $34 \%$, $P<0.001)$, further analysis was divided into two separate groups.

Operative extraction was the most common reason for the claim, followed by ordinary extraction, and apicoectomy of a single-rooted tooth (Table 1). Operative extraction was more often related to removal of a third molar than of other teeth (88 vs. $27 \%, P<0.001$ ), whereas ordinary extraction was more common for other teeth than for third molars (34 vs. $10 \%$, $P<0.001)$.

The most common reasons for claims involving the entire material were injury of the LN (23\%), followed by injury of the IAN (18\%), and infection (14\%). Other reasons for claims included perforation of the maxillary sinus, damage to the neighboring teeth, remnant of a root fragment, fracture of the alveolar or jaw bone, problem with the temporomandibular joint, and burns or scars. The prevalence of these accounted for fewer than $10 \%$ of claims in each group. An
Table 1 Distribution of the 877 surgeries of the 852 patient cases according to treatment codes and compared between other teeth and third molars (in percentages); 25 patient cases involved two surgeries, most often a standard extraction and an operative extraction

\begin{tabular}{llllll}
\hline Code & Operation & Total $(\%)$ & Other teeth $(\%)$ & Third molars $(\%)$ & $P$ value \\
\hline EBA00 & Extraction & 17 & 34 & 10 & $P<0.001$ \\
EBA05 & Difficult extraction & 1 & 4 & 0.5 & $P<0.001$ \\
EBA10 & Operative extraction & 71 & 27 & 88 & $P<0.001$ \\
EBA12 & Difficult operative extraction & 0.5 & 0.5 & 1 & n.s. \\
EBA15 & Extraction of several teeth & & \\
EBA20 & Hemisection & 0.2 & 1 & 0 & n.s. \\
EBA30 & Extraction of root & 0.7 & 2 & 0 & n.s. \\
EBA40 & Apicoectomy, single-rooted & 7 & 24 & 0 & n.s. \\
EBA45 & Apicoectomy, multi-rooted & 2 & 6 & 0 & $P<0.001$ \\
EBA99 & Other operative extraction & 0.3 & 0.5 & 0.5 & $P<0.001$ \\
Total & & 100 & 100 & 100 & n.s. \\
\hline
\end{tabular}

n.s. non-significant

${ }^{\mathrm{a}}$ Extraction of at least four teeth from a jaw during infection control 
Fig. 1 Distribution of claims

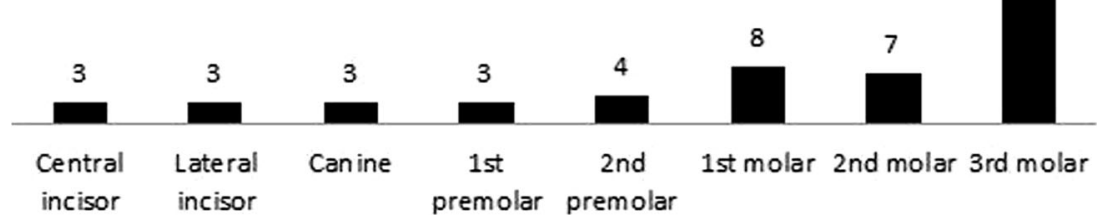

individual case could have several diagnoses. For example, a mandibular fracture could be coupled with an IAN injury.

In this series, the patient received compensation according to the treatment injury (1A) and infection injury (3A) (Table 2). In the authority's final decision on the cases, patients received compensation more often for cases involving third molar than for those involving other teeth (56 vs. $46 \%$, $P<0.05)$.

\section{Discussion}

The main result of this study was that of malpractice claims related to all tooth extractions, the number of cases involving third molars, and especially those involving mandibular ones was superior (Fig. 1). In addition, the principal treatment leading to claims was the operative extraction of a tooth (Table 1). This implies that removing a mandibular third molar is at greater risk for complications than removing other teeth.

A recent study by Jerjes et al. found that the experience and the skill of the operator are imperative in reducing complications from removal of a third molar [9]. They showed that one of the risk factors for both IAN and LN injuries was treatment by trainee surgeons. In a previous study of malpractice claims related to third molar removals, general dentists were responsible for the majority (78\%) of complications, whereas oral and maxillofacial surgeons accounted for $15 \%$, and other dental or medical specialists for $7 \%$ [5]. In addition, more than half of that series of malpractice claims involved dentists with less than 10 years experience. Another recent study involving a smaller portion of the present material focusing on IAN injuries showed that $57 \%$ of claims involved general dentists, $37 \%$ oral and maxillofacial surgeons, $5 \%$ other dental specialists, and $1 \%$ students [6]. Based on the article of the UK's national curriculum of oral surgery for undergraduates, impacted third molars do not belong in core A teaching. Students should familiarize themselves only with the indications, clinical and radiographic examination, and management of impacted teeth, but not be required to perform such procedures [10].

The other main result of the present study was the predominance of nerve injuries as a diagnosis and reason for
Table 2 Comparison of different groups of final decisions regarding other teeth and third molars

\begin{tabular}{lllll}
\hline Code & Type of injury & $\begin{array}{l}\text { Other } \\
\text { teeth }(\%)\end{array}$ & $\begin{array}{l}\text { Third } \\
\text { molars }(\%)\end{array}$ & $P$ value \\
\hline 1A & Treatment injury: compensation paid & 46 & 55 & $P<0.05$ \\
1C & $\begin{array}{l}\text { Treatment injury: no compensation: unavoidable } \\
\text { and not unreasonable }\end{array}$ & 26 & 24 & n.s. \\
1E & $\begin{array}{l}\text { Treatment injury: no compensation: no connection with } \\
\quad \text { examination, treatment, or patient transportation }\end{array}$ & 20 & 5 & $P<0.001$ \\
3A & $\begin{array}{l}\text { Infection injury: compensation paid } \\
\text { 3D }\end{array} \quad \begin{array}{l}\text { Infection injury: no compensation: tolerable } \\
\text { 8C }\end{array} \quad \begin{array}{l}\text { Unspecified: no compensation: unavoidable, } \\
\text { not unreasonable }\end{array}$ & 1 & 1 & n.s. \\
Other & Miscellaneous & 1 & 7 & $P<0.05$ \\
Total & & 6 & 4 & $P<0.01$ \\
\hline
\end{tabular}

n.s. non-significant 
malpractice claims. In our material, LN injury was the dominant reason (23\%) for malpractice claims, and since the outset of the FPIC in 1987 has remained the leading reason [5]. In clinical studies, the prevalence of LN injury is higher than for other nerve injuries. A prospective study of 4338 mandibular third molar extractions showed that LN injury is slightly more prevalent $(0.69 \%)$ than IAN injury $(0.35 \%)$ [4]. In a study of trigeminal nerve injury in 120 cases involving third molar surgery, LN injury accounted for $55.8 \%$ and IAN injury for $44.2 \%$ of the cases [11].

Due to human anatomy, LN and IAN injuries occur during teeth extractions from the mandibular premolar and molar area. The anatomy of the LN is extremely challenging and should be taught in detail already to undergraduates. The LN is located in the lingual soft tissue of the third molar. The nerve can come in contact with the lingual bone and may be located at or above the level of the alveolar crest $[12,13]$. The LN can be damaged by an anesthetic needle or grasping with forceps, during removal of the bone, splitting of the tooth, removal of the follicle, or during suturing. During third molar surgery, the anatomy of the LN should be kept in mind in order to avoid damaging it.

Patients most often received compensation due to treatment injury and more often from removals of third molars than of other teeth (Table 2). This means that the authority determined that the injury could have been avoided had an experienced operator performed the procedure.

In conclusion, because the mandibular third molar was the reason for the majority of malpractice claims, removal of this tooth necessitates recent and high-quality panoramic radiograph, preoperative assessment of the difficulty of removal, and consciousness of the variable anatomical course of LN in order to reduce the numbers of LN and IAN injuries.

\section{Compliance with ethical standards}

Conflict of interest The authors declare that they have no conflict of interest.

Funding The work was not supported by any grants.

Ethical approval This article does not contain any studies with human participants or animals performed by any of the authors.
Informed consent For this type of study, formal consent is not required.

\section{References}

1. Bodner L, Brennan P, McLeod N (2011) Characteristics of iatrogenic mandibular fractures associated with tooth removal: review and analysis of 189 cases. Br J Oral Maxillofac Surg 49:567-572

2. Bui C, Seldin E, Dodson T (2003) Types, frequencies, and risk factors for complications after third molar extraction. J Oral Maxillofac Surg 61:1379-1389

3. Bataineh A (2001) Sensory nerve impairment following mandibular third molar surgery. J Oral Maxillofac Surg 59:1012-1017

4. Cheung L, Leung Y, Chow L, Wong M, Chan E, Fok Y (2010) Incidence of neurosensory deficits and recovery after lower third molar surgery: a prospective clinical study of 4338 cases. Int J Oral Maxillofac Surg 39:320-326

5. Ventä I, Lindqvist C, Ylipaavalniemi P (1998) Malpractice claims for permanent nerve injuries related to third molar removals. Acta Odontol Scand 56:193-196

6. Suomalainen A, Apajalahti S, Vehmas T, Ventä I (2013) Availability of CBCT and iatrogenic alveolar nerve injuries. Acta Odontol Scand 71:151-156

7. Patient Insurance Centre. Safeguarding patients and nursing staff. http://www.pvk.fi/en/. Accessed 6 Jun 2016

8. Nordic Centre for Classifications in Health Care (2011) NOMESCO Classification of Surgical Procedures (NCSP). WHO-FIC Collaborating Centre in the Nordic Countries. http://www.nordclass.se/ncsp_e.htm. Accessed 6 Jun 2016

9. Jerjes W, Upile T, Shah P et al (2010) Risk factors associated with injury to the inferior alveolar and lingual nerves following third molar surgery - revisited. Oral Surg Oral Med Oral Pathol Oral Radiol Endod 109:335-345

10. Macluskey M, Durham J, Cowan G et al (2008) UK national curriculum for undergraduate oral surgery subgroup for teaching of the Association of British Academic Oral and Maxillofacial Surgeons. Eur J Dent Educ 12:48-58

11. Renton T, Yilmaz Z, Gaballah K (2012) Evaluation of trigeminal nerve injuries in relation to third molar surgery in a prospective patient cohort. Recommendations for prevention. Int J Oral Maxillofac Surg 41:1509-1518

12. Kiesselbach JE, Chamberlain JG (1984) Clinical and anatomic observations on the relationship of the lingual nerve to the mandibular third molar region. J Oral Maxillofac Surg 42:565-567

13. Pogrel AM, Renaut A, Schmidt B, Ammar A (1995) The relationship of the lingual nerve to the mandibular third molar region: an anatomic study. J Oral Maxillofac Surg 53:1178-1181 